\title{
Intrauterine Environment and Polycystic Ovary Syndrome
}

\author{
Daniel A. Dumesic, MD ${ }^{1}$ Mark O. Goodarzi, MD, $\mathrm{PhD}^{2}$ Gregorio D. Chazenbalk, $\mathrm{PhD}^{1}$ \\ David H. Abbott, $\mathrm{PhD}^{3,4}$
}

1 Department of Obstetrics and Gynecology, David Geffen School of
Medicine at UCLA, Los Angeles, California
2 Division of Endocrinology, Diabetes, and Metabolism, Department of
Medicine, Cedars-Sinai Medical Center, Los Angeles, California
${ }^{3}$ Wisconsin National Primate Research Center, Madison, Wisconsin
${ }^{4}$ Department of Obstetrics and Gynecology, University of Wisconsin,
Madison, Wisconsin

Address for correspondence Daniel A. Dumesic, MD, Department Obstetrics and Gynecology, David Geffen School of Medicine at UCLA, 10833 Le Conte Avenue, Room 22-178 CHS, Los Angeles, CA 90095 (e-mail: ddumesic@mednet.ucla.edu).

Semin Reprod Med 2014;32:159-165

\begin{abstract}
The maternal-fetal environment plays an important role in developmental programming of adult disease. Metabolic and hormonal dysfunction during human fetal development accompanies gestational diabetes as a common occurrence in mothers with polycystic ovary syndrome (PCOS), while human fetal androgen excess from congenital adrenal hyperplasia or virilizing tumors precedes PCOS-like symptoms after birth. To date, clinical studies of infant blood levels at term have yet to confirm that human fetal androgen excess promotes PCOS development after birth. Earlier in development, however, circulating androgen levels in the second trimester female human fetus can normally rise into the male range. Furthermore, midgestational amniotic testosterone levels are elevated in female fetuses of PCOS compared with

Keywords

- polycystic ovary syndrome

- hyperandrogenism

- hyperinsulinemia

- adiposity

- developmental programming

- fetal development normal mothers and might influence fetal development because experimentally induced fetal androgen excess in animals produces a PCOS-like phenotype with reproductive and metabolic dysfunction. Such alterations in the maternal-fetal environment likely program adult PCOS by epigenetic modifications of genetic susceptibility of the fetus to PCOS after birth. Understanding this phenomenon requires advanced fetal surveillance technologies and postnatal assessment of midgestational androgen exposure for new clinical strategies to improve reproduction in PCOS women, optimize long-term health of their offspring, and minimize susceptibility to acquiring PCOS in future generations.
\end{abstract}

Polycystic ovary syndrome (PCOS) is a heterogeneous syndrome in women characterized by luteinizing hormone (LH) hypersecretion, ovarian hyperandrogenism, oligo-anovulation, and hyperinsulinemia from insulin resistance. The 1990 National Institutes of Health (NIH)-National Institute of Child Health and Human Development Conference of PCOS in 1990 recommended that the diagnostic criteria should be hyperandrogenism and/or hyperandrogenemia with oligoanovulation, excluding other endocrinopathies, including congenital adrenal hyperplasia (CAH), Cushing syndrome, thyroid dysfunction, hyperprolactinemia, androgen-producing tumors, and drug-induced androgen excess. ${ }^{1}$ With a $6.6 \%$ estimated prevalence of NIH-defined PCOS in the United States, the annual economic burden of treating PCOS-related diabetes, menstrual dysfunction, and anovulatory infertility was $\$ 4.4$ billion in 2005 , not considering inflation or pregnancy-related complications, including gestational diabetes, preeclampsia, and miscarriage. $^{2}$

In 2003, the Rotterdam consensus expanded the diagnostic criteria of PCOS to include at least two of the following
Issue Theme Developmental Origins and Future Fate in PCOS: Providence or Peril?; Guest Editor, Kathleen M. Hoeger, MD, $\mathrm{MPH}$
Copyright (C) 2014 by Thieme Medical Publishers, Inc., 333 Seventh Avenue, New York, NY 10001, USA. Tel: +1(212) 584-4662.
DOI http://dx.doi.org/ 10.1055/s-0034-1371087. ISSN 1526-8004. 
Table 1 Reduced second to fourth digit (finger) ratio as a marker of androgen excess in utero in women with PCOS ${ }^{16-19}$

\begin{tabular}{|l|l|l|l|}
\hline Author & Participant & PCOS definition & Findings \\
\hline Cattrall et al 2005 & $\begin{array}{l}70 \text { PCOS } \\
70 \mathrm{NL} \text { women }\end{array}$ & NIH & $\begin{array}{l}\text { Reduced 2D:4D ratio in right hand of } \\
\text { PCOS vs. normal women }\end{array}$ \\
\hline Lujan et al 2010 & $\begin{array}{l}98 \mathrm{PCOS} \\
51 \mathrm{NL} \text { women }\end{array}$ & Rotterdam & $\begin{array}{l}\text { No difference 2D:4D ratio; 2D:4D ratio positively } \\
\text { correlates with hirsutism, free androgen index, } \\
\text { and ovarian volume }\end{array}$ \\
\hline Lujan et al 2010 & $\begin{array}{l}96 \mathrm{PCOS} \\
48 \mathrm{NL} \text { women } \\
50 \text { men }\end{array}$ & Rotterdam & $\begin{array}{l}\text { No difference 2D:4D ratio by computer analysis; } \\
\text { 2D:4D ratio positively correlates with hirsutism, testosterone, } \\
\text { and free androgen index }\end{array}$ \\
\hline Palomba et al 2012 & $\begin{array}{l}30 \text { PCOS } \\
545 \mathrm{NL} \text { women }\end{array}$ & $\begin{array}{l}\text { Rotterdam } \\
\text { (all androgen excess) }\end{array}$ & $\begin{array}{l}\text { Increased 2D:4D ratio in 4-11 years old daughters of } \\
\text { PCOS vs. normal mothers }\end{array}$ \\
\hline
\end{tabular}

Abbreviation: NIS, National Institutes of Health; NL, normal; PCOS, polycystic ovary syndrome.

three features: (1) clinical or biochemical hyperandrogenism, (2) oligo-anovulation, and (3) polycystic ovaries (PCOs), excluding the previously described endocrinopathies. ${ }^{3}$ These newer Rotterdam criteria for PCOS combine all patients defined by 1990 NIH criteria (i.e., classic PCOS) with additional women with either (1) clinical/biochemical hyperandrogenism and PCO (i.e., ovulatory PCOS) or (2) PCO with ovulatory dysfunction (but without signs of androgen excess). As a result, the 6 to $10 \%$ worldwide prevalence of PCOS by $1990 \mathrm{NIH}$ criteria has increased to about twice that level using broader Rotterdam criteria due to the inclusion of multiple PCOS phenotypes. ${ }^{4-6}$ As the most common PCOS phenotype, classic PCOS has the greatest reproductive and metabolic dysfunction, ${ }^{7,8}$ while ovulatory PCOS patients have a lower body mass index (BMI) and lesser degrees of hyperinsulinemia and hyperandrogenism than classic PCOS patients. Women with combined PCO and oligo-anovulation (without androgen excess), who do not fulfill the diagnosis of PCOS by the Androgen Excess Society, appear least affected. ${ }^{7-9}$

Emerging data suggest that the phenotypic expression of adult PCOS may be influenced by the endocrine-metabolic status of the maternal-fetal environment. ${ }^{5}$ This hypothesis agrees with the increased prevalence of PCOS in women with classical CAH from 21 hydroxylase deficiency or congenital adrenal virilizing tumors, ${ }^{10-13}$ and with the ability of discrete experimentally induced prenatal testosterone excess to program a permanent PCOS-like phenotype in several species. ${ }^{14}$

This article addresses the developmental origins of PCOS, whereby maternal maladaptations to pregnancy at a critical gestational age permanently alter fetal susceptibility to PCOS phenotypic expression after birth. This theory of developmental origins of PCOS is based on the premise that alterations in the maternal-fetal environment permanently program adult disease by epigenetic modifications of genetic susceptibility of the fetus to disease after birth.

\section{Endocrine Antecedent to Polycystic Ovary Syndrome}

Women with congenital adrenal virilizing tumors or classical CAH from 21 hydroxylase deficiency have an increased risk of developing a PCOS-like syndrome in adulthood. ${ }^{10-13}$ Such gestational susceptibility to androgens implicates exposure of the female fetus to androgen excess as a modifier of PCOS phenotypic expression after birth. To date, however, a relationship between hyperandrogenism in utero and PCOS phenotypic expression in adulthood has been elusive. Women born to the opposite sex twins, for example, do not display an increased prevalence of PCOS-like features, although presumably they share a prenatal environment with a male co-twin that increases their exposure to testosterone. ${ }^{15}$ Using relative finger length as an anatomical marker of in utero androgen exposure, some, ${ }^{16,17}$ but not all, ${ }^{18,19}$ women with PCOS have altered length of the second finger relative to the fourth finger as a male characteristic that correlates with hyperandrogenism and ovarian volume (-Table 1). ${ }^{18-20}$ Adult female rhesus monkeys with PCOS-like features induced by early-to-midgestation testosterone excess also exhibit alteration of the same finger length ratio, implying an association between PCOS and finger length mediated by prenatal androgen excess. ${ }^{21}$ Elevated umbilical cord testosterone levels also occur in some, ${ }^{22,23}$ but not all, ${ }^{24,25}$ newborns of mothers with PCOS, but such study findings are inconsistent, perhaps from differences in placental steroidogenesis ${ }^{24,25}$ or to cord blood collection at term, ${ }^{22,24,26}$ a time point past the critical period of human ovarian differentiation. ${ }^{27-29}$

Perhaps more importantly, amniotic fluid testosterone levels in the second trimester of human development are normally higher in the male than in the female fetus, allowing a wider range of testosterone levels to differentially affect fetal development compared with term umbilical vein blood testosterone concentrations that are similar between sexes. ${ }^{30}$ Second trimester amniotic fluid testosterone levels also are elevated in female fetuses of PCOS compared with normal mothers (- Table 2 ), ${ }^{17}$ suggesting that androgen overproduction can occur during human female fetal development under certain pregnancy conditions. ${ }^{31}$ Given these findings, therefore, androgen action during the second trimester of human development may influence the developmental programming of the female fetus, assuming a critical time interval in a susceptible fetus when developmental programming occurs. 
Table 2 Second trimester amniotic fluid testosterone levels $(\mathrm{nmol} / \mathrm{L})$ from pregnant women with and without hyperandrogenic polycystic ovary syndrome ${ }^{17}$

\begin{tabular}{|c|c|c|c|}
\hline & $N$ & Mean & SD \\
\hline \multicolumn{4}{|l|}{ Control mothers } \\
\hline Male fetus & 21 & $0.80^{\mathrm{a}}$ & 0.16 \\
\hline Female fetus & 24 & 0.36 & 0.10 \\
\hline \multicolumn{4}{|l|}{ PCOS mothers } \\
\hline Male fetus & 17 & $0.87^{\mathrm{a}}$ & 0.21 \\
\hline Female fetus & 13 & $0.53^{\mathrm{b}}$ & 0.12 \\
\hline
\end{tabular}

Abbreviations: PCOS, polycystic ovary syndrome; SD, standard deviation. ${ }^{\mathrm{a}} p<0.001$ fetal sex difference.

${ }^{\mathrm{b}} p<0.02$ female fetus, control versus PCOS mother.

\section{Ontogeny of the Human Fetal Ovary}

If true, a pivotal issue is the ability of the second trimester human fetal ovary to produce androgen during early folliculogenesis. Human ovarian folliculogenesis begins in early fetal development, when germ cells migrate to the gonadal ridge and multiply by mitosis until approximately 20 weeks of gestation, reaching a maximum number of approximately 7 million (-Fig. 1). ${ }^{32}$ Oogonial mitosis becomes superimposed with meiosis between 14 and 26 weeks of gestation, as ovigerous cords, packed with oogonia and oocytes, develop into abundant primordial and primary follicles, along with occasional secondary follicles. ${ }^{27}$ Simultaneously, a loose network of primary interstitial cells, containing 17a hydroxylase17, 20-lyase (P450c17), the major steroidogenic enzyme responsible for androgen production, develops within the stroma as it differentiates in response to local paracrine factors, including extracellular matrix proteins, or fibrillins. ${ }^{27,33}$ Prominent between 15 and 19 weeks of gestation, these primary interstitial cells ${ }^{27}$ are replaced between 27 and 32 weeks of gestation by other P450c17 immunoreactive cells, which collect around growing primary follicles to form the theca interna layer of emerging secondary and small Graafian follicles, joined shortly thereafter by additional

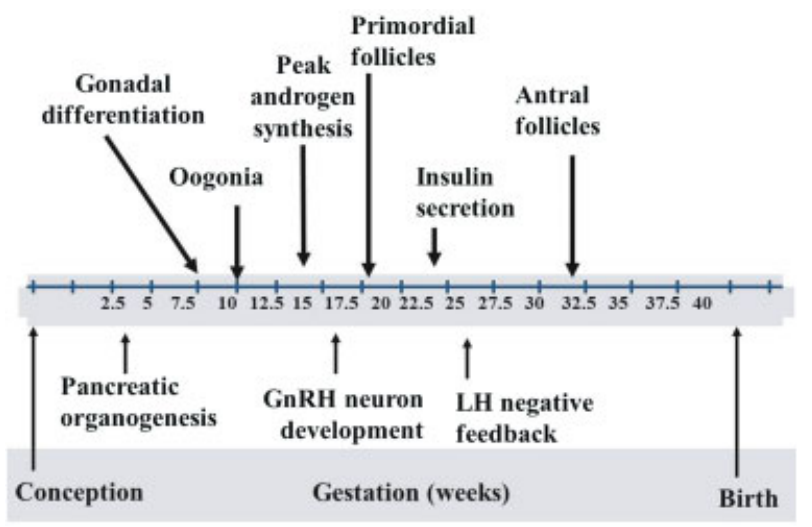

Figure 1 Ontogeny of human fetal development.
P450c17 immunoreactive cells in the hilum. By midgestation, the human fetal ovary has the capacity to produce and detect sex steroids, including androgen and estrogen, ${ }^{27,29,34-38}$ with estrogen believed to regulate folliculogenesis and oocyte development in utero. ${ }^{39-41}$ Together, endocrine (i.e., gonadotropins) and paracrine facilitators of follicular growth (i.e., androgens, growth factors such as activin and insulin-like growth factors [IGF]) interact with survival and atresia factors to establish the maximal germ cell endowment of the fetal ovary, which then diminishes to approximately 1 to 2 million at birth and 300,000 by menarche. ${ }^{28,32}$

During the second trimester of human fetal development, a transient rise of pituitary gonadotropins increases androgen production by the testes compared with the ovary, temporarily elevating circulating androgen levels in the male compared with the female fetus. ${ }^{28,42}$ This sexual dimorphism in androgen production by the human fetus disappears by birth. ${ }^{28,42}$ At midgestation, human fetal ovaries also have several steroidogenic enzymes; genes encoding multiple steroid signaling pathways; and receptors to steroids, insulin, IGF-I, and IGF-II. ${ }^{27,29,34,35}$ They do not, however, have functional LH-like receptors. ${ }^{37}$ Nevertheless, cultured human fetal ovaries at this gestational age can metabolize pregnenolone sulfate to dehydroepiandrosterone (DHEA) and androstenedione $^{36}$ and also can secrete in decreasing amounts DHEA, progesterone, and estrone, with lesser amounts of androstenedione, estradiol, and testosterone. ${ }^{37}$

Therefore, although lacking functional LH-like receptors, midgestational human fetal ovaries may produce androgens in vivo, particularly in response to insulin, which may contribute to wide variation in fetal androgen production, as evidenced by $40 \%$ of midgestational female fetuses having elevated serum androgen levels into the normal male range. ${ }^{41,42}$ This hypothesis agrees with previous reports in diabetic women of elevated amniotic fluid testosterone levels, ${ }^{43}$ along with findings of hirsutism, ovarian thecalutein cysts, and thecal cell hyperplasia in their female stillbirth offspring. ${ }^{44,45}$

\section{Abnormalities of the PCOS Maternal-Fetal Environment}

To date, however, the link between androgen excess in utero and the maternal environment remains unclear. Maternal serum androgen levels in midgestation are greater in PCOS than in normal women, ${ }^{46}$ but are unlikely to directly program PCOS in offspring if placental aromatization is normal, ${ }^{26}$ even though reduced aromatase activity in term placenta from women with PCOS likely contributes to elevated maternal androgen production. ${ }^{25}$ Rather, an increased risk of developing maternal glucose intolerance in women with PCOS may induce intrauterine hyperglycemia, which may stimulate fetal insulin release as a secretagogue for ovarian androgen production and/or folliculogenesis in the female fetus. ${ }^{47-50}$ In support of this, prenatal testosterone administration to female rhesus monkeys impairs maternal-fetal glucose-insulin homeostasis and stimulates fetal insulin release, ${ }^{51}$ consistent with several animal models establishing links 
between gestational hyperglycemia, fetal androgen excess, and various adult PCOS-like phenotypes. ${ }^{52}$

Such maternal-fetal environment dysfunction may underlie several endocrine antecedents of PCOS previously reported in girls born to mothers with PCOS. For example, infant girls born to mothers with PCOS exhibit antimullerian hormone overproduction as a marker of growing follicles, which persists in prepubertal life (along with exaggerated ovarian responsiveness to leuprolide administration) and improves when mothers with PCOS receive metformin in pregnancy, beginning at or before conception. ${ }^{53,54}$ In addition, serum leptin levels in newborns of PCOS women positively correlate with birth weight and maternal BMI at midgestation. ${ }^{55}$ During puberty, enlarged ovaries and hyperinsulinemia in female children of PCOS women coexist with LH hypersecretion and androgen excess. ${ }^{56-58}$

In addition to glucose intolerance, PCOS women in pregnancy are also at increased risk of developing diabetes, pregnancyinduced hypertension, preeclampsia, preterm birth, impaired endovascular trophoblast invasion, and abnormal placentation, ${ }^{17,47-50,59}$ all of which may alter developmental programming of the infant. Successful fetal adaptation to maternal nutrient overabundance favors the development of large-forgestational age infants, contributing to the positive association between maternal BMI at term and infant birth weight. ${ }^{24,60,61}$ On the contrary, impaired fetal nutrient availability from placental insufficiency likely accompanies low infant birth weight associated with maternal diabetes, ${ }^{61}$ PCOS pregnancies in Chilean and Iranian women, ${ }^{23,62}$ and precocious puberty accompanying PCOS in northern Spanish women. ${ }^{63}$ Therefore, different pathophysiological mechanisms, based on the endocrine-metabolic status of the maternal-fetal environment, likely influence the birth weight of infants born to PCOS women.

Such pathophysiological mechanisms may also exert subtle developmental programming effects on the fetus after birth despite normal infant birth weight. ${ }^{24,50,64-67}$ For example, exposure of female rhesus monkeys to prenatal testosterone excess impairs fetal glucose-insulin homeostasis without affecting infant birth weight and alters the trajectory of neonatal growth after birth. ${ }^{51}$ As adults, female rhesus monkeys exposed to prenatal testosterone show disrupted development of subcutaneous abdominal adipocytes, ${ }^{68} \mathrm{mim}$ icking androgen inhibition of human adipose stem cell commitment to preadipocyte formation ${ }^{69}$ and possible effects on a more primitive population of human adipose stem cells with pluripotent stem characteristics. ${ }^{70}$

\section{Genetic and Epigenetic Mechanisms}

The inherited nature of PCOS has been well established by family and twin studies. The prevalence of PCOS in female first-degree relatives of affected women is 20 to $40 \%$, substantially higher than the general population prevalence. ${ }^{71,72}$ Twin studies comparing the correlation of PCOS diagnosis between monozygotic and dizygotic twins have estimated the heritability of PCOS as 70\%, suggesting that most susceptibility arises from genetic factors. ${ }^{73}$ Heritability is commonly assumed to reflect the effects of inherited genomic variation; however, it may also reflect the effects from shared diseasepredisposing environments. The latter is particularly relevant when considering that adverse intrauterine environments may contribute to disease risk, for example, daughters of a woman with PCOS would be exposed to the same intrauterine environment. Thus, fetal androgen excess and consequent reprogramming may contribute to some portion of the $70 \%$ heritability.

Despite little progress in candidate gene studies of small sample sizes, genome-wide association studies (GWAS) in large Chinese cohorts with robust replication recently have identified variants in 11 genomic regions (loci) as risk factors for PCOS. ${ }^{74,75}$ Assuming the gene nearest to each variant is responsible for the risk-altering effect, the GWAS discoveries include DENND1A, LHCGR, THADA, FSHR, C9orf3, YAP1, RAB5B/ SUOX, HMGA2, TOX3, INSR, and SUMO1P1. Only LHCGR, FSHR, and INSR, which encode receptors for $\mathrm{LH} / \mathrm{hCG}, \mathrm{FSH}$, and insulin, respectively, have clear functional relevance to the pathophysiology of PCOS. How the remaining genes might influence PCOS remains unknown.

Nevertheless, variants in some of these established PCOS susceptibility genes might influence fetal reprogramming of PCOS by altering (1) fetal or maternal androgen production, (2) fetal responsiveness to androgen exposure, (3) placental steroid production or clearance, or (4) placenta-related (e.g., placental insufficiency, abnormal placentation) as well as pregnancy-related (e.g., preeclampsia, pregnancy-induced hypertension, gestational diabetes) complications. For example, perhaps fetal ovaries with inherited PCOS-predisposing variants in $L H C G R$, unlike normal fetal ovaries, ${ }^{37}$ express functional receptors, promoting excessive LH-stimulated androgen production at midgestation. Alternatively, INSR variation may increase fetal ovarian responsiveness to insulin, thereby promoting ovarian androgen production in the fetus in response to its own hyperinsulinemia from maternal hyperglycemia. That several PCOS genes (THADA, HMGA2, and $S U O X$ ) have also been implicated in diabetes ${ }^{76-78}$ raises the possibility that fetal reprogramming is related to disturbed maternal-fetal glucose homeostasis. Equally important, several of these loci (LHCGR/FSHR region, INSR, and TOX3) are associated with anthropometric measures (BMI, waist circumference, and height), ${ }^{79,80}$ which could affect fetal reprogramming through fetal growth, while C9orf3 codes for aminopeptidase $\mathrm{O}$, a testicular and placental protease generating angiotensin IV from angiotensin III, ${ }^{81}$ which might promote placental dysfunction, pregnancy-induced hypertension, and fetal androgen excess.

Although the molecular mechanism of reprogramming by intrauterine events is unknown, epigenetic changes induced by an altered in utero environment is a likely mechanism. ${ }^{82}$ Epigenetic refers to modifications of genomic DNA that can be passed to subsequent generations (such as DNA methylation and histone modification), allowing the environment to have permanent changes on gene expression. Rodents ${ }^{83,84}$ and rhesus monkeys ${ }^{85}$ experimentally exposed to androgen excess in utero have been found to exhibit alterations in DNA methylation at specific genes. Of interest, one of these genes is $L H C G R$, ${ }^{83}$ one of 
the susceptibility genes discovered by GWAS in humans, ${ }^{75}$ which demethylated would likely be overexpressed and capable of promoting fetal androgen excess and enhancing LH stimulation of adipogenesis. ${ }^{86}$ Such altered LH signaling in visceral fat of LH hypersecreting infant and adult monkeys, exposed to androgen excess in utero, has been linked with differential DNA methylation of specific gene promoter sites in this fat depot, ${ }^{85}$ which may be constrained by testosterone in its capacity to safely store fat. ${ }^{68,69}$

\section{Future Directions}

Future studies need to examine how alterations in the maternal-fetal environment program adult PCOS by epigenetic modifications of fetal genetic susceptibility to PCOS after birth. If metabolic disorders of pregnancy, such as PCOS, obesity, and diabetes mellitus, induce androgen overproduction by the midgestational human fetal ovary, then advanced fetal surveillance technologies and postnatal assessment of intrauterine androgen exposure will be required to understand whether adult PCOS can be reprogramed in susceptible female offspring. Equally important, abnormal placentation may simultaneously affect fetal adaptation to maternal nutrient availability, with altered placental DNA methylation ${ }^{87}$ or other epigenetic and metabolic abnormalities influencing fetal growth, infant birth weight, and long-term physiology of the offspring. ${ }^{43,88,89}$ As the number of robust susceptibility loci for PCOS emerges from ongoing GWAS data, additional studies will be needed to interrogate the possible role of these genes in fetal reprogramming of PCOS.

Finally, experimental constraints on using human fetal tissue for biomedical research limit our knowledge of the relationships between the human fetus and its maternal environment. Therefore, new knowledge of how developmental programming affects human health requires animal models to explore the probable fetal origins of adult disease. Such animal studies need to examine how developmentally relevant endocrine/paracrine factors and genes interact to govern human fetal development, including the role of ovarian steroidogenesis in the developmental programming of target tissues. With such information, new clinical strategies promise to improve the endocrine-metabolic status of women with PCOS in pregnancy, optimize long-term health of their offspring, and minimize susceptibility to acquiring PCOS and its metabolic derangements in future generations.

Acknowledgment

This study was funded by a grant from The Eunice Kennedy Shriver National Institute of Child Health and Human Development (NICHD), NIH, through cooperative agreement U54 HD071836.

\section{References}

1 Zawadzki J, Dunaif A. Diagnostic criteria for polycystic ovary syndrome: towards a rational approach. In: Dunaif A, Givens JR, Haseltine FP, Merriam GR, eds. Polycystic Ovary Syndrome. Boston, MA: Blackwell Scientific; 1992:377-384
2 Azziz R, Marin C, Hoq L, Badamgarav E, Song P. Health care-related economic burden of the polycystic ovary syndrome during the reproductive life span. J Clin Endocrinol Metab 2005;90(8): 4650-4658

3 Rotterdam ESHRE/ASRM-Sponsored PCOS Consensus Workshop Group. Revised 2003 consensus on diagnostic criteria and longterm health risks related to polycystic ovary syndrome (PCOS). Hum Reprod 2004;19(1):41-47

4 Azziz R, Woods KS, Reyna R, Key TJ, Knochenhauer ES, Yildiz BO. The prevalence and features of the polycystic ovary syndrome in an unselected population. J Clin Endocrinol Metab 2004;89(6): 2745-2749

5 Fauser BCJM, Tarlatzis BC, Rebar RW, et al. Consensus on women's health aspects of polycystic ovary syndrome (PCOS): the Amsterdam ESHRE/ASRM-Sponsored 3rd PCOS Consensus Workshop Group. Fertil Steril 2012;97(1):28-38, e25

6 March WA, Moore VM, Willson KJ, Phillips DIW, Norman RJ, Davies MJ. The prevalence of polycystic ovary syndrome in a community sample assessed under contrasting diagnostic criteria. Hum Reprod 2010;25(2):544-551

7 Carmina E, Chu MC, Longo RA, Rini GB, Lobo RA. Phenotypic variation in hyperandrogenic women influences the findings of abnormal metabolic and cardiovascular risk parameters. J Clin Endocrinol Metab 2005;90(5):2545-2549

8 Welt CK, Gudmundsson JA, Arason G, et al. Characterizing discrete subsets of polycystic ovary syndrome as defined by the Rotterdam criteria: the impact of weight on phenotype and metabolic features. J Clin Endocrinol Metab 2006;91(12):4842-4848

9 Azziz R, Carmina E, Dewailly D, et al; Androgen Excess Society. Positions statement: criteria for defining polycystic ovary syndrome as a predominantly hyperandrogenic syndrome: an Androgen Excess Society guideline. J Clin Endocrinol Metab 2006;91(11):4237-4245

10 Barnes RB, Rosenfield RL, Ehrmann DA, et al. Ovarian hyperandrogynism as a result of congenital adrenal virilizing disorders: evidence for perinatal masculinization of neuroendocrine function in women. J Clin Endocrinol Metab 1994;79(5):1328-1333

11 Merke DP, Cutler GB Jr. New ideas for medical treatment of congenital adrenal hyperplasia. Endocrinol Metab Clin North Am 2001;30(1):121-135

12 Phocas I, Chryssikopoulos A, Sarandakou A, Rizos D, Trakakis E. A contribution to the classification of cases of non-classic 21-hydroxylase-deficient congenital adrenal hyperplasia. Gynecol Endocrinol 1995;9(3):229-238

13 Stikkelbroeck NM, Hermus AR, Braat DD, Otten BJ. Fertility in women with congenital adrenal hyperplasia due to 21-hydroxylase deficiency. Obstet Gynecol Surv 2003;58(4):275-284

14 Dumesic DA, Abbott DH, Padmanabhan V. Polycystic ovary syndrome and its developmental origins. Rev Endocr Metab Disord 2007;8:127-141

15 Kuijper EAM, Vink JM, Lambalk CB, Boomsma DI. Prevalence of polycystic ovary syndrome in women from opposite-sex twin pairs. J Clin Endocrinol Metab 2009;94(6):1987-1990

16 Cattrall FR, Vollenhoven BJ, Weston GC. Anatomical evidence for in utero androgen exposure in women with polycystic ovary syndrome. Fertil Steril 2005;84(6):1689-1692

17 Palomba S, Marotta R, Di Cello A, et al. Pervasive developmental disorders in children of hyperandrogenic women with polycystic ovary syndrome: a longitudinal case-control study. Clin Endocrinol (Oxf) 2012;77(6):898-904

18 Lujan ME, Bloski TG, Chizen DR, Lehotay DC, Pierson RA. Digit ratios do not serve as anatomical evidence of prenatal androgen exposure in clinical phenotypes of polycystic ovary syndrome. Hum Reprod 2010;25(1):204-211

19 Lujan ME, Podolski AJ, Chizen DR, Lehotay DC, Pierson RA. Digit ratios by computer-assisted analysis confirm lack of anatomical evidence of prenatal androgen exposure in clinical phenotypes of polycystic ovary syndrome. Reprod Biol Endocrinol 2010; 8:156-163 
20 Lutchmaya S, Baron-Cohen S, Raggatt P, Knickmeyer R, Manning JT. 2nd to 4th digit ratios, fetal testosterone and estradiol. Early Hum Dev 2004;77(1-2):23-28

21 Abbott AD, Colman RJ, Tiefenthaler R, Dumesic DA, Abbott DH. Early-to-mid gestation fetal testosterone increases right hand 2D:4D finger length ratio in polycystic ovary syndrome-like monkeys. PLoS ONE 2012;7(8):e42372

22 Barry JA, Kay AR, Navaratnarajah R, et al. Umbilical vein testosterone in female infants born to mothers with polycystic ovary syndrome is elevated to male levels. J Obstet Gynaecol 2010; 30(5):444-446

23 Mehrabian F, Kelishadi R. Comparison of the metabolic parameters and androgen level of umbilical cord blood in newborns of mothers with polycystic ovary syndrome and controls. J Res Med Sci 2012;17(3):207-211

24 Anderson H, Fogel N, Grebe SK, Singh RJ, Taylor RL, Dunaif A. Infants of women with polycystic ovary syndrome have lower cord blood androstenedione and estradiol levels. J Clin Endocrinol Metab 2010;95(5):2180-2186

25 Maliqueo M, Lara HE, Sánchez F, Echiburú B, Crisosto N, SirPetermann T. Placental steroidogenesis in pregnant women with polycystic ovary syndrome. Eur J Obstet Gynecol Reprod Biol 2013; 166(2):151-155

26 Hickey M, Sloboda DM, Atkinson HC, et al. The relationship between maternal and umbilical cord androgen levels and polycystic ovary syndrome in adolescence: a prospective cohort study. J Clin Endocrinol Metab 2009;94(10):3714-3720

27 Cole B, Hensinger K, Maciel GAR, Chang RJ, Erickson GF. Human fetal ovary development involves the spatiotemporal expression of p450c17 protein. J Clin Endocrinol Metab 2006;91(9):3654-3661

28 Mesiano S. The endocrinology of human pregnancy and fetoplacental neuroendocrine development. In: Strauss JF III, Barbieri RL, eds. Yen and Jaffe's Reproductive Endocrinology: Physiology, Pathophysiology, and Clinical Management. 6th ed. Philadelphia, PA: Saunders Elsevier; 2009:248-281

29 Fowler PA, Anderson RA, Saunders PT, et al. Development of steroid signaling pathways during primordial follicle formation in the human fetal ovary. J Clin Endocrinol Metab 2011;96(6): $1754-1762$

30 van de Beek C, Thijssen JHH, Cohen-Kettenis PT, van Goozen SHM, Buitelaar JK. Relationships between sex hormones assessed in amniotic fluid, and maternal and umbilical cord serum: what is the best source of information to investigate the effects of fetal hormonal exposure? Horm Behav 2004;46(5):663-669

31 Goodarzi MO, Dumesic DA, Chazenbalk G, Azziz R. Polycystic ovary syndrome: etiology, pathogenesis and diagnosis. Nat Rev Endocrinol 2011;7(4):219-231

32 Adashi EY. The ovarian follicular apparatus. In: Adashi EY, Rock JA, Rosenwaks Z, eds. Reproductive Endocrinology, Surgery, and Technology. Philadelphia, PA: Lippincott-Raven; 1996:18-40

33 Hatzirodos N, Bayne RA, Irving-Rodgers HF, et al. Linkage of regulators of TGF- $\beta$ activity in the fetal ovary to polycystic ovary syndrome. FASEB J 2011;25(7):2256-2265

34 Voutilainen R, Miller WL. Developmental expression of genes for the stereoidogenic enzymes P450scc (20,22-desmolase), P450c17 (17 alpha-hydroxylase/17,20-lyase), and P450c21 (21-hydroxylase) in the human fetus. J Clin Endocrinol Metab 1986;63(5): $1145-1150$

35 Shifren JL, Osathanondh R, Yeh J. Human fetal ovaries and uteri: developmental expression of genes encoding the insulin, insulinlike growth factor I, and insulin-like growth factor II receptors. Fertil Steril 1993;59(5):1036-1040

36 Payne AH, Jaffe RB. Androgen formation from pregnenolone sulfate by the human fetal ovary. J Clin Endocrinol Metab 1974; 39(2):300-304

37 Wilson EA, Jawad MJ. The effect of trophic agents on fetal ovarian steroidogenesis in organ culture. Fertil Steril 1979; 32(1):73-79
38 George FW, Wilson JD. Conversion of androgen to estrogen by the human fetal ovary. J Clin Endocrinol Metab 1978;47(3):550-555

39 Pepe GJ, Billiar RB, Albrecht ED. Regulation of baboon fetal ovarian folliculogenesis by estrogen. Mol Cell Endocrinol 2006;247(1-2): 41-46

40 Albrecht ED, Pepe GJ. Estrogen regulation of placental angiogenesis and fetal ovarian development during primate pregnancy. Int J Dev Biol 2010;54(2-3):397-408

41 Reyes FI, Winter JS, Faiman C. Studies on human sexual development. I. Fetal gonadal and adrenal sex steroids. J Clin Endocrinol Metab 1973;37(1):74-78

42 Beck-Peccoz P, Padmanabhan V, Baggiani AM, et al. Maturation of hypothalamic-pituitary-gonadal function in normal human fetuses: circulating levels of gonadotropins, their common alphasubunit and free testosterone, and discrepancy between immunological and biological activities of circulating follicle-stimulating hormone. J Clin Endocrinol Metab 1991;73(3):525-532

43 Barbieri RL, Saltzman DH, Torday JS, Randall RW, Frigoletto FD, Ryan $\mathrm{KJ}$. Elevated concentrations of the $\beta$-subunit of human chorionic gonadotropin and testosterone in the amniotic fluid of gestations of diabetic mothers. Am J Obstet Gynecol 1986;154(5):1039-1043

44 Driscoll SG, Benirschke K, Curtis GW. Neonatal deaths among infants of diabetic mothers. Postmortem findings in ninety-five infants. Am J Dis Child 1960;100:818-835

45 Hultquist GT, Olding LB. Endocrine pathology of infants of diabetic mothers. A quantitative morphological analysis including a comparison with infants of iso-immunized and of non-diabetic mothers. Acta Endocrinol Suppl (Copenh) 1981;241(Suppl):1-202

46 Sir-Petermann T, Maliqueo M, Angel B, Lara HE, Pérez-Bravo F Recabarren SE. Maternal serum androgens in pregnant women with polycystic ovarian syndrome: possible implications in prenatal androgenization. Hum Reprod 2002;17(10):2573-2579

47 Boomsma CM, Eijkemans MJC, Hughes EG, Visser GHA, Fauser BCJM, Macklon NS. A meta-analysis of pregnancy outcomes in women with polycystic ovary syndrome. Hum Reprod Update 2006;12(6):673-683

48 Kjerulff LE, Sanchez-Ramos L, Duffy D. Pregnancy outcomes in women with polycystic ovary syndrome: a metaanalysis. Am J Obstet Gynecol 2011;204:1-6

49 Altieri P, Gambineri A, Prontera O, Cionci G, Franchina M, Pasquali R. Maternal polycystic ovary syndrome may be associated with adverse pregnancy outcomes. Eur J Obstet Gynecol Reprod Biol 2010;149(1):31-36

50 Bjercke S, Dale PO, Tanbo T, Storeng R, Ertzeid G, Abyholm T. Impact of insulin resistance on pregnancy complications and outcome in women with polycystic ovary syndrome. Gynecol Obstet Invest 2002;54(2):94-98

51 Abbott DH, Bruns CR, Barnett DK, et al. Experimentally-induced gestational androgen excess disrupts glucoregulation in rhesus monkey dams and their female offspring. Am J Physiol Endocrinol Metab 2010;299:E741-E751

52 Padmanabhan V, Veiga-Lopez A. Developmental origin of reproductive and metabolic dysfunctions: androgenic versus estrogenic reprogramming. Semin Reprod Med 2011;29(3):173-186

53 Sir-Petermann T, Codner E, Maliqueo M, et al. Increased antiMüllerian hormone serum concentrations in prepubertal daughters of women with polycystic ovary syndrome. J Clin Endocrinol Metab 2006;91(8):3105-3109

54 Crisosto N, Echiburú B, Maliqueo M, et al. Improvement of hyperandrogenism and hyperinsulinemia during pregnancy in women with polycystic ovary syndrome: possible effect in the ovarian follicular mass of their daughters. Fertil Steril 2012;97(1):218-224

55 Maliqueo M, Echiburú B, Crisosto N, et al. Metabolic parameters in cord blood of newborns of women with polycystic ovary syndrome. Fertil Steril 2009;92(1):277-282

56 Crisosto N, Codner E, Maliqueo M, et al. Anti-Müllerian hormone levels in peripubertal daughters of women with polycystic ovary syndrome. J Clin Endocrinol Metab 2007;92(7):2739-2743 
57 Kent SC, Gnatuk CL, Kunselman AR, Demers LM, Lee PA, Legro RS. Hyperandrogenism and hyperinsulinism in children of women with polycystic ovary syndrome: a controlled study. J Clin Endocrinol Metab 2008;93(5):1662-1669

58 Sir-Petermann T, Codner E, Pérez V, et al. Metabolic and reproductive features before and during puberty in daughters of women with polycystic ovary syndrome. J Clin Endocrinol Metab 2009; 94(6):1923-1930

59 Yamamoto M, Feigenbaum SL, Crites Y, et al. Risk of preterm delivery in non-diabetic women with polycystic ovarian syndrome. J Perinatol 2012;32(10):770-776

60 Cresswell JL, Barker DJ, Osmond C, Egger P, Phillips DI, Fraser RB. Fetal growth, length of gestation, and polycystic ovaries in adult life. Lancet 1997;350(9085):1131-1135

61 Mumm H, Kamper-Jørgensen M, Nybo Andersen AM, Glintborg D, Andersen M. Birth weight and polycystic ovary syndrome in adult life: a register-based study on 523,757 Danish women born 19731991. Fertil Steril 2013;99(3):777-782

62 Sir-Petermann T, Hitchsfeld C, Maliqueo M, et al. Birth weight in offspring of mothers with polycystic ovarian syndrome. Hum Reprod 2005;20(8):2122-2126

63 Ibáñez L, Potau N, Francois I, de Zegher F. Precocious pubarche, hyperinsulinism, and ovarian hyperandrogenism in girls: relation to reduced fetal growth. J Clin Endocrinol Metab 1998;83(10): 3558-3562

64 Legro RS, Roller RL, Dodson WC, Stetter CM, Kunselman AR, Dunaif A. Associations of birthweight and gestational age with reproductive and metabolic phenotypes in women with polycystic ovarian syndrome and their first-degree relatives. J Clin Endocrinol Metab 2010;95(2):789-799

65 Laitinen J, Taponen S, Martikainen H, et al. Body size from birth to adulthood as a predictor of self-reported polycystic ovary syndrome symptoms. Int J Obes Relat Metab Disord 2003;27(6):710-715

66 Haakova L, Cibula D, Rezabek K, Hill M, Fanta M, Zivny J. Pregnancy outcome in women with PCOS and in controls matched by age and weight. Hum Reprod 2003;18(7):1438-1441

67 Mikola M, Hiilesmaa V, Halttunen M, Suhonen L, Tiitinen A. Obstetric outcome in women with polycystic ovarian syndrome. Hum Reprod 2001;16(2):226-229

68 Chazenbalk GD, Aguilera P, Keller E, Dumesic DA, Abbott DH. Altered transition of adipose stem cell commitment to early preadipocyte differentiation in subcutaneous abdominal adipose tissue of adult PCOS-like female rhesus monkeys. Paper presented at the 95th Annual Meeting of the Endocrine Society; June 15-18, 2013; San Francisco, CA, Poster Mon-555

69 Chazenbalk G, Singh P, Irge D, Shah A, Abbott DH, Dumesic DA. Androgens inhibit adipogenesis during human adipose stem cell commitment to preadipocyte formation. Steroids 2013;78(9): 920-926

70 Heneidi S, Simerman AA, Keller E, et al. Awakened by cellular stress: isolation and characterization of a novel population of pluripotent stem cells derived from human adipose tissue. PLoS ONE 2013;8(6):e64752

71 Legro RS, Driscoll D, Strauss JF III, Fox J, Dunaif A. Evidence for a genetic basis for hyperandrogenemia in polycystic ovary syndrome. Proc Natl Acad Sci U S A 1998;95(25):14956-14960

72 Kahsar-Miller MD, Nixon C, Boots LR, Go RC, Azziz R. Prevalence of polycystic ovary syndrome (PCOS) in first-degree relatives of patients with PCOS. Fertil Steril 2001;75(1):53-58
73 Vink JM, Sadrzadeh S, Lambalk CB, Boomsma DI. Heritability of polycystic ovary syndrome in a Dutch twin-family study. J Clin Endocrinol Metab 2006;91(6):2100-2104

74 Chen ZJ, Zhao H, He L, et al. Genome-wide association study identifies susceptibility loci for polycystic ovary syndrome on chromosome 2p16.3, 2p21 and 9q33.3. Nat Genet 2011;43(1): $55-59$

75 Shi Y, Zhao H, Shi Y, et al. Genome-wide association study identifies eight new risk loci for polycystic ovary syndrome. Nat Genet 2012;44(9):1020-1025

76 Zeggini E, Scott LJ, Saxena R, et al; Wellcome Trust Case Control Consortium. Meta-analysis of genome-wide association data and large-scale replication identifies additional susceptibility loci for type 2 diabetes. Nat Genet 2008;40(5):638-645

77 Voight BF, Scott LJ, Steinthorsdottir V, et al; MAGIC investigators; GIANT Consortium. Twelve type 2 diabetes susceptibility loci identified through large-scale association analysis. Nat Genet 2010;42(7):579-589

78 Hakonarson $\mathrm{H}, \mathrm{Qu} \mathrm{HQ}$ Bradfield JP, et al. A novel susceptibility locus for type 1 diabetes on Chr12q13 identified by a genomewide association study. Diabetes 2008;57(4):1143-1146

79 Lango Allen H, Estrada K, Lettre G, et al. Hundreds of variants clustered in genomic loci and biological pathways affect human height. Nature 2010;467(7317):832-838

80 Fox CS, Heard-Costa N, Cupples LA, Dupuis J, Vasan RS, Atwood LD. Genome-wide association to body mass index and waist circumference: the Framingham Heart Study 100K project. BMC Med Genet 2007;8(Suppl 1):S18

81 Díaz-Perales A, Quesada V, Sánchez LM, et al. Identification of human aminopeptidase $O$, a novel metalloprotease with structural similarity to aminopeptidase B and leukotriene A4 hydrolase. J Biol Chem 2005;280(14):14310-14317

82 Li Z, Huang H. Epigenetic abnormality: a possible mechanism underlying the fetal origin of polycystic ovary syndrome. Med Hypotheses 2008;70(3):638-642

83 Zhu JQ, Zhu L, Liang XW, Xing FQ, Schatten H, Sun QY. Demethylation of LHR in dehydroepiandrosterone-induced mouse model of polycystic ovary syndrome. Mol Hum Reprod 2010;16(4):260-266

84 Qu F, Wang FF, Yin R, et al. A molecular mechanism underlying ovarian dysfunction of polycystic ovary syndrome: hyperandrogenism induces epigenetic alterations in the granulosa cells. J Mol Med (Berl) 2012;90(8):911-923

$85 \mathrm{Xu}$ N, Kwon S, Abbott DH, et al. Epigenetic mechanism underlying the development of polycystic ovary syndrome (PCOS)-like phenotypes in prenatally androgenized rhesus monkeys. PLoS ONE 2011;6(11):e27286

86 Dos Santos E, Dieudonné MN, Leneveu MC, Pecquery R, Serazin V, Giudicelli Y. In vitro effects of chorionic gonadotropin hormone on human adipose development. J Endocrinol 2007;194(2):313-325

87 Park BH, Kim YJ, Park JS, et al. Folate and homocysteine levels during pregnancy affect DNA methylation in human placenta [in Korean]. J Prev Med Pub Health 2005;38(4):437-442

88 Rees WD, Wilson FA, Maloney CA. Sulfur amino acid metabolism in pregnancy: the impact of methionine in the maternal diet. J Nutr 2006;136(6, Suppl):1701S-1705S

89 Kwong WY, Miller DJ, Wilkins AP, et al. Maternal low protein diet restricted to the preimplantation period induces a gender-specific change on hepatic gene expression in rat fetuses. Mol Reprod Dev 2007;74(1):48-56 